
\title{
is Research Square \\ Isolation of Nannocystis species from Iran and exploring their natural products
}

\author{
Azam Moradi \\ Shahid Beheshti University \\ Mohammad Yaghoubi-Avini ( $\nabla$ m_yaghoubi@sbu.ac.ir) \\ Shahid Beheshti University https://orcid.org/0000-0001-5761-1062 \\ Joachim Wink \\ Helmholtz-Zentrum fur Infektionsforschung $\mathrm{GmbH}$
}

\section{Research Article}

Keywords: myxobacteria, Nannocystiacea, isolation, taxonomy, cytotoxic, one strain many compounds

Posted Date: September 20th, 2021

DOl: https://doi.org/10.21203/rs.3.rs-906260/v1

License: (1) This work is licensed under a Creative Commons Attribution 4.0 International License.

Read Full License

Version of Record: A version of this preprint was published at Archives of Microbiology on January 7th, 2022. See the published version at https://doi.org/10.1007/s00203-021-02738-0. 


\section{Abstract}

Several different techniques were employed for the isolation of Nannocystis from various sources. A polyphasic approach was used for identification. Twelve strains of N. pusilla, N. exedens, and N. konarekensis with distinctive distribution between climates were identified. The bioactivity was examined against a panel of eight bacteria, two yeasts, and one fungus; cytotoxicity was tested on the L929 fibroblast cell line. Eleven strains mainly inhibit Gram-positive bacteria, and only one isolate was cytotoxic. The extracts analysis by HPLC and LC-MS were compared to Myxobase, and eight different compounds were detected; a correlation was observed between compounds and producing species. $70 \%$ of strains had the potential to produce structurally diverse compounds. Nannochelins and althiomycin were the most abundant metabolites. The discovery of a new species of Nannocystis and the high potentiality of strains to produce secondary metabolites encourage further sampling and in-depth analysis of extracts to find new active metabolites.

\section{Introduction}

Myxobacteria are a fascinating monophyletic group of $\delta$-proteobacteria, with a large genome ranging between 8 to $13 \mathrm{Mb}$. Their complex life cycle includes two stages: the vegetative stage, in which rodshaped cells of myxobacteria swarm on solid surfaces and prey on other bacteria or decompose cellulose. In unfavorable conditions, the cells undergo morphogenesis and exhibit an organized social behavior to develop fruiting bodies that contain heat-stable myxospores (Reichenbach and Dworkin 1992). The genus Nannocystis, with its three species and some genera of marine myxobacteria, constitutes the family Nannocystaceae in the Nannocystineae suborder of myxobacteria (Mohr 2018). Metagenomics studies revealed the wide distribution of myxobacteria in both terrestrial and aquatic environments. Indeed, Myxococcales form the $4 \%$ of OTUs in soil samples that is the fourth abundant taxa in this habitat (Zhou et al. 2014). Metagenomic studies revealed an outstanding diversity in myxobacteria with 20 suborders that only strains of Sorangiineae, Cystobacterineae, and Nannocystineae were cultured and extensively explored for their secondary metabolites (Zhou et al. 2014). Nannocystis are considered ubiquitous myxobacteria that are mainly isolated from soil and decaying plants in diverse geographical locations. The vegetative cells of this genus have short, slender, or fat rods with small spherical sporangioles. Their colorless colonies excavate agar in a nutrient-poor medium. They live in mesophilic temperatures and degrade organic matter in aerobic conditions (Müller 2014).

Myxobacteria are famous for their high capabilities to produce diverse secondary metabolites. They are the second most proliferative producers of these compounds after Actinobacteria. Until now, more than 100 new core structures and over 600 derivatives are characterized in myxobacteria (Weissman and Müller 2010). However, only four structural varieties are reported from Nannocystis and, their potential for the production of natural products is less studied (Herrmann et al. 2017).

Previous studies showed isolation of every new species, genus, or family increases the chance of encountering new natural products, respectively (Hoffmann et al. 2018). One way to isolate such new 
taxonomic groups is to search for new habitats because every ecological niche has its specific condition and microbiome that provoke certain symbiosis relationships between microbes. Thus, myxobacteria isolation efforts in under-explored environments introduce the chance of encountering new bioactive metabolites. In turn, it may help to overcome antibiotic resistance in pathogens.

The objective of this study was to thoroughly examine the less studied species of Nannocystis in Iran and characterize their natural products and bioactivities.

\section{Materials And Methods Sample collection}

Multiple samples were collected from May 2013 to February 2015, from 45 stations located in Caspian shore, temperate forests of Mazandaran, the central desert of Iran, deserts of Sistan \& Baluchistan, mountainous area of Zagreus, grasslands of northern Khorasan and Azerbaijan, and the coast and islands of the Persian Gulf. These samples include topsoil, decaying woods and barks, rabbit dungs, beach sands, and freshwater. The samples were shipped to the laboratory in capped bottles and dried at room temperature and darkness.

\section{Isolation of strains}

Three methods were employed to isolate Nannocystis species:

I. WCX media $\left(0.15 \% \mathrm{Cacl}_{2} \cdot 2 \mathrm{H}_{2} \mathrm{O}, 0.15 \% \mathrm{MgSO}_{4} \cdot 7 \mathrm{H}_{2} \mathrm{O}, 50 \mathrm{mM}\right.$ HEPES, $100 \mathrm{mg} / \mathrm{ml}$ cycloheximide, $1.8 \%$ agar, $\mathrm{pH} 7.2$ ) supplemented with $1 \mathrm{ml} / \mathrm{L}$ vitamin solution ( $0.2 \%$ biotin, $2 \%$ nicotinic acid, $1 \%$ thiamine, $1 \%$ 4-aminobenzoic acid, $0.5 \%$ pantothenate, $5 \%$ pyridoxamine, $2 \%$ cyanocobalamin, filter sterilized) cross streaked with live $E$. coli as bait and inoculated with pea-sized samples in the tips of lines. Inoculated media incubated at $30^{\circ} \mathrm{C}$ for up to 8 weeks. The plates were investigated twice a week for characteristics of the swarm and fruiting bodies of Nannocystis by the stereomicroscope (Olympus SZX-10, Japan).

II. Four pieces of filter paper $(2 \times 2 \mathrm{~cm})$ were placed on ST21 agar (Shimkets et al. 2006) containing 100 $\mu \mathrm{g} / \mathrm{ml}$ cycloheximide and a pea-sized sample transferred to the center of the filter papers. The plates were incubated at $30^{\circ} \mathrm{C}$ for eight weeks and searched for fruiting bodies and swarms twice a week by the stereomicroscope.

III. Freshwater samples were filtered through a sterile nitrocellulose membrane filter $(0.45 \mu \mathrm{m}$, Sartorius, USA). The filters were transferred to the rabbit dung agar (Shimkets et al. 2006) and incubated at $34^{\circ} \mathrm{C}$. After 3-4 days, plates were studied under the stereomicroscope.

\section{Purification of cultures}

Because of the massive contamination of isolation plates, application of the following protocols was necessary to purify the Nannocystis isolates: 
1. The tip of young fruiting bodies or the edge of swarms was picked by a sterile needle under a stereomicroscope and transferred to the center of the CY or VY/2 agar plate (Reichenbach and Dworkin 1992). Repeating this procedure several times results in pure cultures.

2. An antibiotic solution (Table 1) was prepared and distributed on the surface of the CY, VY/2, or WAT agars by a Drigalsky bar. After the solution adsorption, the vegetative cells or fruiting bodies of Nannocystis strains were inoculated to the center of these media and incubated at $30^{\circ} \mathrm{C}$.

3. The same method also was used to reveal antibiotic resistance patterns of purified strains.

Table 1

Antibiotic solutions for purification of Nannocystis isolates

\begin{tabular}{|ll|}
\hline Antibiotic stock solutions & Final concentration \\
\hline Ampicillin $10 \mathrm{mg} / \mathrm{ml}$ & $100 \mu \mathrm{g} / \mathrm{ml}$ \\
\hline Bacitracin $10 \mathrm{mg} / \mathrm{ml}$ & $50 \mu \mathrm{g} / \mathrm{ml}$ \\
\hline Cephalosporin $10 \mathrm{mg} / \mathrm{ml}$ & $50 \mu \mathrm{g} / \mathrm{ml}$ \\
\hline Chloramphenicol $9 \mathrm{mg} / \mathrm{ml}^{\text {a }}$ & $30 \mu \mathrm{g} / \mathrm{ml}$ \\
\hline Fusidic acid $10 \mathrm{mg} / \mathrm{ml}$ & $50 \mu \mathrm{g} / \mathrm{ml}$ \\
\hline Gentamicin $10 \mathrm{mg} / \mathrm{ml}$ & $50 \mu \mathrm{g} / \mathrm{ml}$ \\
\hline Hygromycin $50 \mathrm{mg} / \mathrm{ml}$ & $150 \mu \mathrm{g} / \mathrm{ml}$ \\
\hline Kanamycin $10 \mathrm{mg} / \mathrm{ml}$ & $50 \mu \mathrm{g} / \mathrm{ml}$ \\
\hline Oxytetracycline $10 \mathrm{mg} / \mathrm{ml}$ & $10 \mu \mathrm{g} / \mathrm{ml}$ \\
\hline Polymycin $10 \mathrm{mg} / \mathrm{ml}$ & $50 \mu \mathrm{g} / \mathrm{ml}$ \\
\hline Spectinomycin $10 \mathrm{mg} / \mathrm{ml}$ & $50 \mu \mathrm{g} / \mathrm{ml}$ \\
\hline Trimethoprim $5 \mathrm{mg} / \mathrm{ml}$ a & $50 \mu \mathrm{g} / \mathrm{ml}$ \\
\hline Thiosterpton $10 \mathrm{mg} / \mathrm{ml}{ }^{\mathrm{b}, \mathrm{c}}$ & $50 \mu \mathrm{g} / \mathrm{ml}$ \\
\hline a in methanol & \\
\hline b in DMSO & \\
\hline c stored at $-20^{\circ} \mathrm{C}$ & \\
\hline
\end{tabular}

For long-term storage, a piece of WAT agar medium with fully developed fruiting bodies was cut and placed on a sterile filter paper on a plate and dried under the vacuum between 2 to 3 days. The paper cuts were recovered in a cryovial under the sterilized condition and stored at room temperature.

\section{Identification and phylogenetic analysis}


The images were taken from the fruiting bodies, fringes of swarms, and the vegetative cells grown on CY or VY/2 agar by the stereomicroscope and under $40 \mathrm{X}$ magnification. The taxonomy was presumed by comparing morphological features with Bergey's Manual of Systematic Bacteriology (Reichenbach 2005) and The Prokaryotes (Rolf Muller 2014).

The homogenates of strains cultivated in liquid media were used to determine biochemical profiles by API ZYM® (bioMérieux, France) rapid tests. VY/2 agar cultures incubated at 22,30 , and $44^{\circ} \mathrm{C}$ for 1 to 3 weeks used for determination of optimum growth temperatures and strains cultured at $30^{\circ} \mathrm{C}$ for $1-3$ weeks on the same medium prepared in $\mathrm{pH} 5,6,7,8$, and 9 indicate the best growth condition.

The genomic DNA was extracted with the Gram-negative protocol of the spin plant mini kit (Invitek, Germany). Amplification of 16S rDNA was done by PCR using F27 and R1525 universal primers and the following conditions: initial denaturation $5 \mathrm{~min}$ at $95^{\circ} \mathrm{C}, 34$ cycles of denaturation at $95^{\circ} \mathrm{C}$ for $0.5 \mathrm{~min}$, annealing at $52^{\circ} \mathrm{C}$ for $0.5 \mathrm{~min}$, and extension at $72^{\circ} \mathrm{C}$ for $0.5 \mathrm{~min}$, and a final extension at $72^{\circ} \mathrm{C}$ for $10 \mathrm{~min}$. The PCR products were separated by electrophorese on $0.8 \%$ agarose gel to determine amplicon size and purified using NucleoSpin Extract II (Macherey-Nagel, Germany). 16S rDNA sequenced by Sanger dideoxy method and contigs assembled by Seqman II software (Ver 6.00) using default settings. The isolates were identified by comparing their contigs with type strain sequences in the EzBiocloud database (Yoon et al. 2017). Multiple alignment and curation were performed by MUSCLE and Gblocks, respectively, using phylogeny.fr web tools (Dereeper et al. 2008). The phylogenetic analysis was conducted by MEGA-X software (Kumar et al. 2018), applying the Maximum-Likelihood method and Hasegawa-Kishino-Yano model (Hasegawa et al. 1985) with a bootstrap analysis of 100 replications. The sequences were submitted to the Genbank database of $\mathrm{NCBI}$, and the accession numbers are obtainable from the phylogenetic tree (Fig. 3).

\section{Secondary metabolite production and extraction}

The agar pieces containing fruiting bodies or swarms from a pure culture were excised and transferred to a $20 \mathrm{ml}$ of myxovirescin medium ( $1.0 \%$ casein peptone, $0.005 \% \mathrm{CaCl}_{2}, 0.025 \% \mathrm{MgSO}_{4}, 1 \mathrm{mg} / \mathrm{CoCl}_{2}$, $100 \mathrm{mM}$ HEPES, pH 7.0) amended with $10 \%$ A medium ( $0.8 \%$ starch, $0.4 \%$ soy flour, $0.2 \%$ yeast, $0.1 \%$ $\mathrm{CaCl}_{2}, 0.1 \% \mathrm{MgSO}_{4}, 100 \mathrm{mM} \mathrm{HEPES}, 1 \mathrm{ml} / \mathrm{F} \mathrm{Fe}-\mathrm{EDTA}, 4 \mathrm{ml} / \mathrm{I}$ glycerin, $\mathrm{pH}$ 7.4) and vitamin B12 (final concentration, $500 \mu \mathrm{g} / \mathrm{l})$, the fermentation experienced for $10-14$ days at $30^{\circ} \mathrm{C}$. After this period, Nannocystis has grown to the spherical masses of aggregated cells. The whole medium was used to inoculate $100 \mathrm{ml}$ of the same medium containing 2\% XAD-4 resin (Sigma-Aldrich, USA) and incubated under the same conditions. At the end of fermentation, the resin and biomass were harvested and washed with deionized water, then extracted with acetone for at least 3 hours in darkness. The acetonic extract was dried in a rotary evaporator (Heidolph, Germany) and resolved in $1 \mathrm{ml}$ methanol, and stored at $-20^{\circ} \mathrm{C}$ for further experiments.

\section{Antimicrobial activity and cytotoxicity}


The spectrum of antibacterial activity of each crude extract was determined by micro broth dilution method against Gram-positive bacteria Bacillus subtilis (DSM 10), Micrococcus luteus (DSM 1790) and Staphylococcus aureus (Newman), Gram-negative E. coli (DSM 1116), E. coli TolC mutant (DSM 104619), Pseudomonas aeruginosa (PA14) and Chromobacterium violaceum (DSM 30191), Mycobacterium smegmatis (ATCC 700084) and yeasts-Candida albicans (DSM 1665), Pichia anomala (DSM 6766), and filamentous fungus Mucor hiemalis (DSM 2656). The bacteria were cultured in Muller-Hinton broth and diluted by the same medium to the 0.05 turbidity at $600 \mathrm{~nm}$. Yeasts and fungus were cultured in Mycosel broth (Cazin et al., 1989) and were diluted to 0.01 absorbance at $600 \mathrm{~nm}$. One hundred and fifty microliters of the cell suspensions were pipetted to each well of the microtiter plates (Brand, Germany), and $20 \mu \mathrm{l}$ of each crude extract was added to the first row and serially diluted with $150 \mu \mathrm{l}$ of the same suspension. Upon visual investigation on plates, those extracts that inhibit indicator microorganism growth further than row $\mathrm{C}$ were considered bioactive and were chosen for LC-MS studies.

The extracts cytotoxicity was assayed against mouse fibroblast L929 cell line by adding $3 \mu$ l of crud extracts in $87 \mu \mathrm{l}$ of the DMEM medium with $10 \%$ FBS in a microtiter plate. The L929 cells were cultured under a $5 \% \mathrm{CO}_{2}$ atmosphere for seven days at $37^{\circ} \mathrm{C}$. After this period, the cells were washed twice by PBS buffer, harvested by the addition of $0.05 \%$ trypsin, and counted using a Neubauer chamber. Subsequently, the cells were diluted to 50000 cells/ml by adding the same medium and $120 \mu \mathrm{l}(6 \times 103$ cells) inoculated to each well. The plates were incubated at $37^{\circ} \mathrm{C}$ for five days and studied under the inverted microscope for morphological changes in the cells.

\section{Fractionation and LC-MS analysis of extracts}

The extracts were fractioned with an HPLC (Agilent 1100) equipped with an X-Bridge C18 column; $3.5 \mu \mathrm{m}$, $2.1 \times 100 \mathrm{~mm}$ (Waters, Milford, USA), and DAD detector (200-400 nm). From each bioactive extract, $5 \mu \mathrm{l}$ were injected into the column and eluted with a gradient of $100 \% \mathrm{~A}: 950 \mathrm{ml}$ of $0.05 \mathrm{mM}$ ammonium acetate buffer, $\mathrm{pH}: 5$ and $50 \mathrm{ml}$ ACN to $100 \% \mathrm{~B}: 0.05 \mathrm{mM}$ ammonium acetate in ACN at $0.3 \mathrm{ml} / \mathrm{min}$ flow rate. Fractions were collected every $30 \mathrm{~s}$ in wells of a microplate and dried at $40^{\circ} \mathrm{C}$ in nitrogen gas flow by a MiniVap (Porvair Sciences, UK). Subsequently, $150 \mathrm{ml}$ of each indicator microorganism that earlier was inhibited by the same extract was added to the wells and incubated at the appropriate conditions. Wells with growth inhibition were compared with the HPLC chromatogram to filtering out crude extracts that their activities attributed to the fatty acids. The others were analyzed further by an LC-MS system made of an Agilent 1200 HPLC with DAD detector (200-600 nm) and a maXis UHR-TOF (Bruker Daltonics, USA) mass spectrometer. The analysis of samples was done by an ACQUITY UPLC BEH C18 (Waters, Milford, USA ) column $2.1 \times 5 \mathrm{~mm}, 1.7 \mathrm{mM}$ in $0.1 \%$ formic acid as solvent $A, 0.1 \%$ formic acid in ACN as solvent $B$ by the gradient of $0.5 \mathrm{~min} 95 \% \mathrm{~A}$; reach to $95 \% \mathrm{~B}$ in $19.5 \mathrm{~min}$ and hold on $95 \% \mathrm{~B}$ for $10 \mathrm{~min}$ at the flow rate of $0.6 \mathrm{ml} / \mathrm{min}$; oven temperature $40^{\circ} \mathrm{C}$. The compounds were identified by comparing mass data, UV spectrums, elution times, and bioactivities with the "Myxobase" database held in Helmholtz Center for Infection Research, Braunschweig, Germany. Correlation between each species and secondary metabolite production was investigated by clustering data with the ClustVis web tool and visualized in a heatmap graph (Metsalu and Vilo 2015). 


\section{Results}

\section{Strains isolation, purification, and identification}

After 2 to 3 weeks of incubation, tiny spherical or elliptical, colorless to dark orange sporangioles of Nannocystis species appeared on or into the agar. Microscopic studies have shown wave-like colorless to yellow swarms that etch agar with blunt-ended short rod cells and round or oval myxospores in sporangioles (Fig. 1). Isolation and purification efforts succeeded in pure cultures of 12 isolates. Phenotypic and phylogenetic markers identified eight strains of $N$. pusilla isolated from 7 stations in temperate forests and Zagros mountains and three strains of $N$. exedens from stations of the central desert (Fig. 2). The type strain of $N$. konarekensis DSM $104509^{\top}$ was isolated from the deserts of southeastern Iran. Table 2 presents sample type, purification method, physiology, and phenotype of strains, except for the N. konarekensis type strain that was described in detail elsewhere (Mohr 2018). 
Table 2

Summary of isolation and purification techniques of Nannocystis species and phenotypic and physiological characteristics.

\begin{tabular}{|c|c|c|c|}
\hline \multicolumn{2}{|l|}{ Species } & \multirow{2}{*}{$\begin{array}{l}\text { N. pusilla } \\
5(3,7,25,166,212)^{a}\end{array}$} & \multirow{2}{*}{$\begin{array}{l}\text { N. exedens } \\
-\end{array}$} \\
\hline $\begin{array}{l}\text { Isolation } \\
\text { biotope }\end{array}$ & $\begin{array}{l}\text { Temperate } \\
\text { forest }\end{array}$ & & \\
\hline & Arid desert & - & $3(51,211,215)$ \\
\hline & Mountainous & $3(34,35,49)$ & - \\
\hline \multirow[t]{2}{*}{$\begin{array}{l}\text { Isolation } \\
\text { sample }\end{array}$} & $\begin{array}{l}\text { Decaying } \\
\text { wood }\end{array}$ & 2 & 3 \\
\hline & topsoil & 6 & - \\
\hline \multirow{2}{*}{$\begin{array}{l}\text { Isolation } \\
\text { media }\end{array}$} & WCX & 2 & - \\
\hline & ST21 & 6 & 3 \\
\hline \multirow{2}{*}{$\begin{array}{l}\text { Purification } \\
\text { method }\end{array}$} & Subculture & 1 & 3 \\
\hline & $\begin{array}{l}\text { Antibiotic } \\
\text { treatment }\end{array}$ & 7 & - \\
\hline \multicolumn{2}{|c|}{ Fruiting bodies on $\mathrm{CY}$ agar } & $\begin{array}{l}\text { Tiny, evenly distributed, } \\
\text { colorless to yellow }\end{array}$ & $\begin{array}{l}\text { Single or clustered sporangioles, } \\
\text { Yellow to dark orange }\end{array}$ \\
\hline \multicolumn{2}{|c|}{ Optimum temperature $\left({ }^{\circ} \mathrm{C}\right)$} & 30 & 30 \\
\hline \multicolumn{2}{|l|}{ Optimum pH } & $7-8$ & 8 \\
\hline \multicolumn{4}{|c|}{ Antibiotic resistance ${ }^{\mathrm{b}}(\mu \mathrm{g} / \mathrm{ml})$} \\
\hline \multicolumn{2}{|c|}{ Bacitracin $(50$ mg/ml) } & - & - \\
\hline \multicolumn{2}{|c|}{ Chloramphenicol (30 mg/ml) } & - & $v$ \\
\hline \multicolumn{2}{|c|}{ Fusidic acid (50 mg/ml) } & + & + \\
\hline \multicolumn{2}{|c|}{ Hygromycin (150 mg/ml) } & - & - \\
\hline \multicolumn{2}{|c|}{ Oxytetracycline $(10 \mathrm{mg} / \mathrm{ml})$} & - & - \\
\hline \multicolumn{2}{|c|}{ Polymycin (50 mg/ml) } & v & - \\
\hline \multicolumn{2}{|c|}{ Spectinomycin $(50$ mg/ml) } & - & - \\
\hline \multicolumn{2}{|c|}{ Trimethoprim (50 mg/ml) } & $\mathrm{v}$ & + \\
\hline \multicolumn{2}{|c|}{ Thiosterpton (50 mg/ml) } & - & - \\
\hline \multicolumn{4}{|c|}{ Enzyme activity (API ZYM) } \\
\hline \multicolumn{2}{|c|}{ Alkaline phosphatase } & 5 & 5 \\
\hline
\end{tabular}


fungus. However, the hypersensitive TolC mutant of $E$. coli was inhibited strongly by the isolate 49 of $N$. pusilla and weakly by isolates 51 and 34. In this regard, only one isolate (212) moderately arrested $M$. smegmatis growth. The granulation and vacuolation of cytoplasm or disruption of monolayer relate to the bioactivity of extracts. Among 12 bioassays were conducted by crude extracts of Nannocystis strains, only the strain 215 extract showed activity with degeneration and vacuolation of the cells (Fig. 4).

Table 3

Bioactivity of pure culture extracts against a panel of sensitive microorganisms.

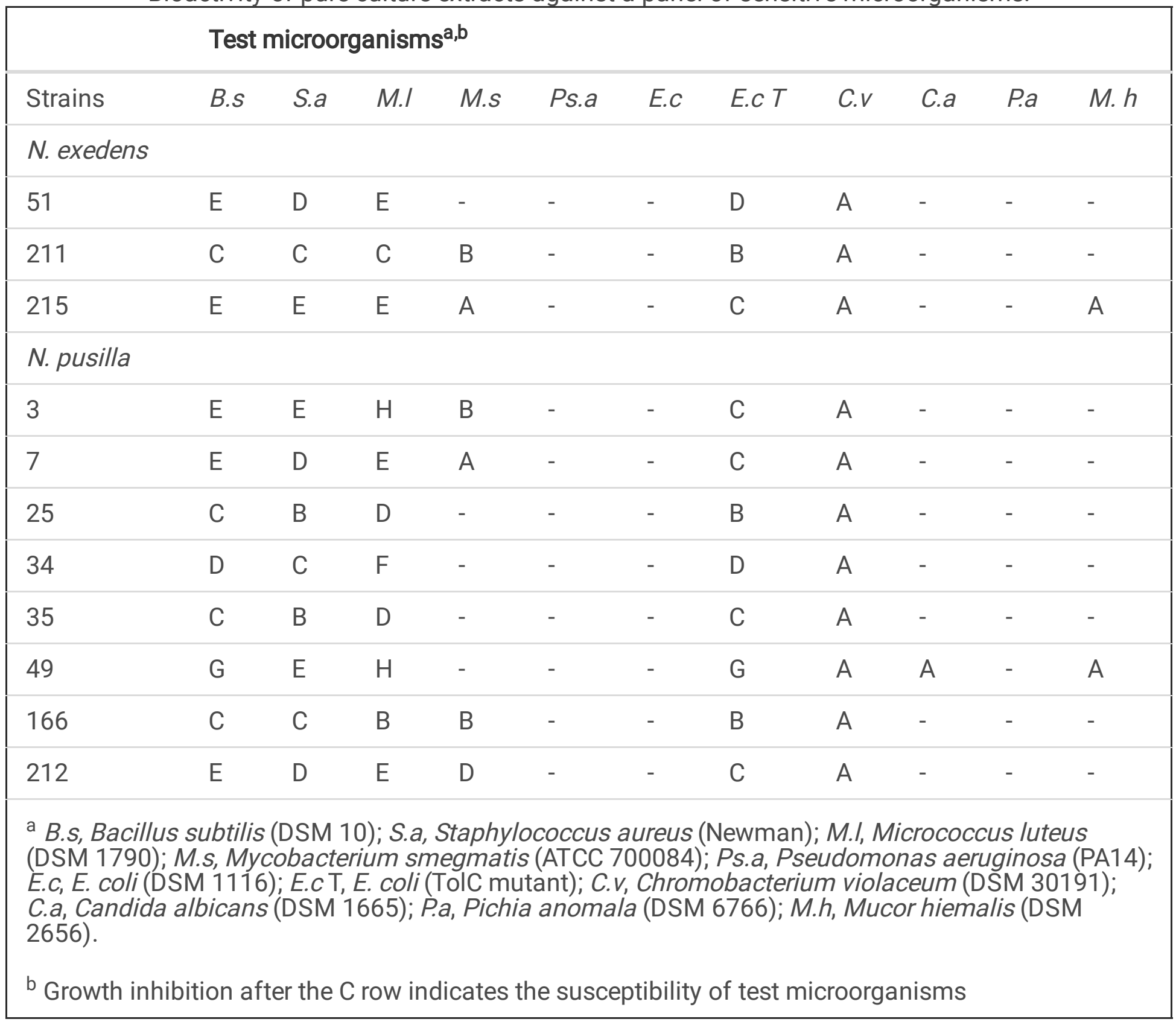

\section{Secondary metabolites}

The HPLC fractionation and LC-MS analysis detected nine secondary metabolites in 10 out of the eleven extracts. Five metabolites were common between different isolates and the other four were produced each by a single strain (Table 4). Also, LC-MS analysis showed two new derivatives of nannochelin and 
myxoprincomide in this study. Myxopyronin, myxoprincomide, and pyrronazol were found exclusively in four strains of $N$. pusilla; on the other hand, myxothiazol and germacrane were solely produced by $N$. exedens 215 . Althiomycin, the potentially new nannochelin and, nannochelin were the most frequented metabolites in the mass spectrums of extracts, respectively. The most fruitful stain was 215 of $N$. exedens that produced four different metabolites, while 7 and 211 each produce one metabolite. Isolates $34,35,51$, and 166 from both species have the same profile of secondary metabolites although, they were from distinct locations and phylogenetically not related. Strain 25 antimicrobial activity was related to fatty acids, as proved by double peaks in $17 \mathrm{~min}$ of the chromatogram. Hierarchical clustering of detected metabolites by species of Nannocystis visualized in the heatmap graph (Fig. 5). There was a strong correlation between nannochelin, germacrane and, myxothiazol with $N$. exedens strains though althiomycin, pyrronazol, and potentially new compounds production were more related to the $N$. pusilla strains exclusively, a new myxoprincomide identified only in the extract of the $N$. pusilla 3 . There is no report of secondary metabolites from $N$. konarekensis.

Table 4

List of secondary metabolites produced by each strain of Nannocystis sp.

\begin{tabular}{|llll|}
\hline & N. pusilla & N. exedens & N. konarekensis \\
\hline Althiomycin & $34,35,166$ & 51 & - \\
\hline Germacrane & - & 215 & - \\
\hline Myxopyronin & 7,212 & - & - \\
\hline New myxoprincomide & 3 & - & - \\
\hline Myxothiazol & - & 215 & - \\
\hline Nannopyrazinone & 3 & 215 & - \\
\hline Nannochelin & 49 & 211,215 & - \\
\hline New nannochelin & $34,35,166$ & 51 & - \\
\hline Pyrronazol & 49 & - & - \\
\hline
\end{tabular}

\section{Discussion}

Among the cultivable myxobacteria, Nannocystineae is the less abundant and more diverse group. Based on a recent metagenomics study, this suborder contains 11 families, 157 genera, and 309 species that only a small number of them (nine species) held in pure cultures (Liu et al. 2019).

The first study on the myxobacteria of Iran concluded that with an average of 7.4 species per sample, this region is one of the most fruitful places for the isolation of myxobacteria (Dawid 2000). This study attributed this finding to the warm summers and humid winters of Iran. Also, it reported N. exedens in 
$58 \%$ of the collected soil samples. The recent study on 62 collected specimens of various types from Iran could not isolate any Nannocystis species, though it used innovative culture media that seem well not suited for Nannocystis isolation (Saadatpour and Mohammadipanah 2020).

In the present study, Nannocystis species were retrieved from $22 \%$ of sampling sites. They formed $14 \%$ of all isolated myxobacteria and included a new species (Mohr 2018). The isolation on ST21 agar was a more efficient method compared to WCX agar because this medium is more enriched and nutritious.

$N$. exedens strains grown mainly from rotten plants of the arid climates, as was suggested previously (Dawid 2000). In contrast, the isolation of N. pusilla strains was more successful from the topsoil layer of northern forests and Zagreus Mountains that have much more vegetation because of increased humidity. $N$. konarekensis again shows more affiliation to hot and dry places. The difference in habitats results in the difference in purification techniques; $N$. pusilla was mainly purified on media containing antibiotic solutions due to the more contaminations of samples, though purification of $N$. exedens was done by several subcultures. The physiology of Nannocystis species closely resembles together and needs careful examination to distinguish between strains. On the other hand, phylogenetic analysis based on partial sequences of $16 \mathrm{~S}$ rDNA discriminates clearly between strains of Nannocystis species. Although, genetic markers such as $r p o B$ (Ogier et al. 2019) or genotyping methods like semi-nested PCR-DGGE (Li et al. 2014), MLSA (Lalucat et al. 2020), and comparative genomics (Livingstone et al. 2018; Chambers et al. 2020) had a better discriminatory power to resolve taxonomy at the species level. These findings emphasize the importance of attention to morphological aspects of swarms and fruiting bodies. Therefore, the polyphasic approach is the most suitable for the identification and classification of Nannocystis.

Seven out of ten secondary metabolites producers have had OSMAC (one strain many compounds) potentiality (Table 4) that synthesized compounds from different structural classes. This phenomenon was previously reported from N. pusilla strains (Bader et al. 2020), but this study revealed both species had such ability. The most notable was $N$. exedens 215 production of the metabolites in the full spectrum of bioactivity from unknown to cytotoxic. Despite their outstanding capability to produce metabolites from different structural classes, strains of this study had a narrow range of bioactivity on Gram-positive bacteria and the E. coli TolC mutant.

Nannochelins and althiomycin were the most abundant secondary metabolites identified in both $N$. pusilla and N. exedens strains. Up to $70 \%$ of the isolates had produced a type of nannochelins. These compounds are citrate-hydroxamate siderophores with the activity on Gram-positive bacteria and weak inhibition of fungi by a still unknown mechanism (Kunze et al. 1992). Althiomycin is a sulfur-containing cyclic peptide, previously isolated from several myxobacteria in Cystobacterineae and Streptomyces that elicits broad antibacterial activity by inhibiting peptidyltransferase reactions [5,25]. All althiomycin producing strains except $N$. pussila 166 inhibited Gram-positive test microorganisms. Also, strains 34 and 51 inhibited TolC mutant $E$. coli in a somewhat weaker manner. 
Nannopyrazinones (nannozinone) and pyrronazols are rare bioactive molecules of $\mathrm{N}$-containing heterocyclic compounds with a weak antibacterial and antifungal activity. Pyrronazols have been identified in extracts of both N. pusilla and N. exedens broths (Jansen et al. 2014a). LC-MS analysis of only one strain (49) of $N$. pusilla showed the peak of pyrronazol consistent with its very weak inhibition of M. hiemalis. Nannopyrazinones were reported from N. pusilla (Jansen et al. 2014b) with an additional slight cytotoxicity effect on the L929 cell line, while analysis indicated these compounds in one strain of each species ( 3 and 215) and therefore it may contribute to the lethal effect of strain 215 on L929 cells (Herrmann et al. 2017).

In addition to nannopyrazinone, $N$. pusilla 3 secreted a potentially new derivative of myxoprincomide to the fermentation broth that is a linear peptide with unusual amino acids. It was discovered in $M$. xanthus DK 1622 broth mass spectrum by metabolome mining and statistical evaluations (Cortina et al. 2012). There is no report of biological activity or mechanism for this metabolite but, increased bioactivity of $N$. pusilla 3 than the reported bioactivity of nannopyrazinones may be due to the synergism between these metabolites.

Strains 7 and 212 of $N$. pusilla produced a single metabolite, myxopyronin, with the a-pyrone structure that inhibits bacterial RNA polymerase by binding to the "switch region" of the molecule (Mukhopadhyay et al. 2008). Myxopyronin was initially reported from M. fulvus and exhibited a broad antibacterial activity against both high and low G + C Gram-positive and some Gram-negatives (Irschik et al. 1983). Screening of bioactivities of these strains (7 and 212) support the identification based on LC-MS with inhibition of all tested Gram-positive bacteria, M. smegmatis and, TolC mutant of E. coli.

Germacrane produced by $N$. exedens 215 is a cyclodecane sesquiterpene previously reported from $N$. exedens (Reichenbach, H.; Höfle 2000). Its biological importance for producing strains is not understood, but derivatives of germacrane in medicinal plants show a broad range of antimicrobial activity and cytotoxicity (Zhang et al. 2018).

Only N. exedens 215 with the production of myxothiazol displayed toxicity to L929 fibroblasts. Myxothiazol was reported for the first time from Myxococcus fulvus strain Mx f16 and structurally belongs to the bithiazole compounds that inhibit respiratory complex III [33,34]. In addition to cytotoxicity, this antibiotic has antifungal activity as seen by slight inhibition of M. hiemalis by N. exedens 215 .

The heatmap clearly shows the distinct distribution of metabolites between species of Nannocystis. Also, Nannocystis in this study shares three metabolites with Myxococcus from the Cystobacterianea suborder. Hoffmann and Krug reveal a correlation between chemical diversity and the taxonomy of myxobacteria; in this study, the profile of known and unknown metabolites of each taxon above the genus rank differs meaningfully from other taxons. Likewise, they found such a correlation between four species of Myxococcus and their metabolites, however, in a less clear state (Hoffmann et al. 2018). Another relevant finding of Hoffmann was near relatedness in secondary metabolites profiles of Myxococcus and Nannocystis genera in unknown and known metabolites (Hoffmann et al. 2018). 
In conclusion, this study presents Iran as an excellent source for the isolation of Nannocystis strains with a high potential for secondary metabolites production. Especially, extensive sampling of dry and remote deserts and islands can result in the identification of new species that increase the chance of encountering new metabolites. According to the production of several natural products by most strains in our collection, novel secondary metabolites may be found by in-depth analysis of MS data and genomes for cryptic biosynthetic pathways. Our findings also emphasize the importance of well-established protocols for the isolation and cultivation of this genus.

\section{Declarations}

\section{Declarations}

\section{Funding}

The authors did not receive support from any organization for the submitted work.

\section{Conflicts of interest}

The authors declare that they have no known competing financial interests or personal relationships that could have appeared to influence the work reported in this paper.

\section{Availability of data and material}

All sequences were deposited in Genbank and are accessible through accession numbers KX572697, KX572719-21, KX572723-24, KX572736,58,88,91, and KX57572856. N. konarekensis type strain is held by DSMZ culture collection under DSM $104509^{\top}$ catalog number.

\section{Code availability}

Not applicable

\section{Ethics approval}

Not applicable

\section{Consent to participate}

Not applicable

Consent for publication

Not applicable

\section{Acknowledgments}


We thank Dr. Gholamhossein Ebrahimipour (Microbiology department, SBU Tehran) for providing provisions in Iran. We are also grateful to Ms. Aileen Gollasch, Ms. Birte Trunkwalter, Ms. Steffi Schulz, and Mr. Klaus Peter Conrad (Microbial Strain Collection, HZI Braunschweig), for excellent laboratory assistance. Many thanks to friends and colleagues who help us for collecting samples all over Iran.

\section{References}

1. Bader CD, Panter F, Müller R (2020) In depth natural product discovery - Myxobacterial strains that provided multiple secondary metabolites. Biotechnol Adv 39:107480.

https://doi.org/10.1016/j.biotechadv.2019.107480

2. Chambers J, Sparks N, Sydney N et al (2020) Comparative Genomics and Pan-Genomics of the Myxococcaceae, including a Description of Five Novel Species: Myxococcus eversorsp. nov., Myxococcus llanfairpwllgwyngyllgogerychwyrndrobwllllantysiliogogogochensis sp. nov., Myxococcus vastatorsp. nov., Pyxidicoccus caerfyrddinensis sp. nov., and Pyxidicoccus trucidator sp. nov. Genome Biol Evol 12:2289-2302. https://doi.org/10.1093/gbe/evaa212

3. Cortina NS, Krug D, Plaza A et al (2012) Myxoprincomide: A Natural Product from Myxococcus xanthus Discovered by Comprehensive Analysis of the Secondary Metabolome. Angew Chemie Int Ed 51:811-816. https://doi.org/10.1002/anie.201106305

4. Dawid W (2000) Biology and global distribution of myxobacteria in soils. FEMS Microbiol Rev 24:403-427

5. Dereeper A, Guignon V, Blanc G et al (2008) Phylogeny.fr: robust phylogenetic analysis for the nonspecialist. Nucleic Acids Res 36:. https://doi.org/10.1093/nar/gkn180

6. Gerth K, Irschik H, Reichenbach H, Trowitzsch W (1980) Myxothiazol, an antibiotic from Myxococcus fulvus (myxobacterales). I. Cultivation, isolation, physico-chemical and biological properties. J Antibiot (Tokyo) 33:1474-1479. https://doi.org/10.7164/antibiotics.33.1474

7. Hasegawa M, Kishino H, Yano T (1985) Dating of the human-ape splitting by a molecular clock of mitochondrial DNA. J Mol Evol 22:160-174. https://doi.org/10.1007/BF02101694

8. Herrmann J, Fayad AA, Müller R (2017) Natural products from myxobacteria: Novel metabolites and bioactivities. Nat Prod Rep 34:135-160. https://doi.org/10.1039/c6np00106h

9. Hoffmann T, Krug D, Bozkurt N et al (2018) Correlating chemical diversity with taxonomic distance for discovery of natural products in myxobacteria. Nat Commun 9:803

10. Irschik H, Gerth K, Reichenbach $\mathrm{H}$ et al (1983) The myxopyronins, new inhibitors of bacterial rna synthesis from myxococcus fulvus (myxobacterales). J Antibiot (Tokyo) 36:1651-1658. https://doi.org/10.7164/antibiotics.36.1651

11. Jansen R, Sood S, Huch V et al (2014a) Pyrronazols, metabolites from the myxobacteria Nannocystis pusilla and N. exedens, are unusual chlorinated pyrone-oxazole-pyrroles. J Nat Prod 77:320-326. https://doi.org/10.1021/np400877r 
12. Jansen R, Sood S, Mohr KI et al (2014b) Nannozinones and sorazinones, unprecedented pyrazinones from myxobacteria. J Nat Prod 77:2545-2552. https://doi.org/10.1021/np500632c

13. Kumar S, Stecher G, Li M et al (2018) MEGA X: Molecular Evolutionary Genetics Analysis across Computing Platforms. Mol Biol Evol 35:1547-1549. https://doi.org/10.1093/molbev/msy096

14. Kunze B, Reichenbach $\mathrm{H}$, Augustiniak H, Höfle $\mathrm{G}$ (1982) Isolation and identification of althiomycin from Cystobacter fuscus (Myxobacterales). J Antibiot (Tokyo) 35:635-636.

https://doi.org/10.7164/antibiotics.35.635

15. Kunze B, Trowitzsch-Kienasi W, Höfle G, Reichenbach H (1992) Nannochelins a, b and c, new ironchelating compounds from nannocystis exedens (myxobacteria): Production, isolation, physicochemical and biological properties. J Antibiot (Tokyo) 45:147-150.

https://doi.org/10.7164/antibiotics.45.147

16. Lalucat J, Mulet M, Gomila M, García-Valdés E (2020) Genomics in bacterial taxonomy: Impact on the genus pseudomonas. Genes (Basel) 11:. https://doi.org/10.3390/genes11020139

17. Li B, Yao Q, Zhu H (2014) Approach to analyze the diversity of myxobacteria in soil by semi-nested PCR-denaturing gradient gel electrophoresis (DGGE) based on taxon-specific gene. PLoS One 9:. https://doi.org/10.1371/journal.pone.0108877

18. Liu Y, Yao Q, Zhu H (2019) Meta-16S rRNA gene phylogenetic reconstruction reveals the astonishing diversity of cosmopolitan myxobacteria. Microorganisms 7 :. https://doi.org/10.3390/microorganisms7110551

19. Livingstone PG, Morphew RM, Whitworth DE (2018) Genome Sequencing and Pan-Genome Analysis of 23 Corallococcus spp. Strains Reveal Unexpected Diversity, With Particular Plasticity of Predatory Gene Sets. Front Microbiol 9:3187. https://doi.org/10.3389/fmicb.2018.03187

20. Metsalu T, Vilo J (2015) ClustVis: a web tool for visualizing clustering of multivariate data using Principal Component Analysis and heatmap. Nucleic Acids Res 43:W566-W570. https://doi.org/10.1093/nar/gkv468

21. Mohr K (2018) Diversity of myxobacteria-we only see the tip of the iceberg. Microorganisms $6: 84$

22. Mukhopadhyay J, Das K, Ismail S et al (2008) The RNA Polymerase "Switch Region" Is a Target for Inhibitors. Cell 135:295-307. https://doi.org/10.1016/j.cell.2008.09.033

23. Ogier JC, Pagès $S$, Galan $M$ et al (2019) RpoB, a promising marker for analyzing the diversity of bacterial communities by amplicon sequencing. BMC Microbiol 19:171. https://doi.org/10.1186/s12866-019-1546-z

24. Reichenbach H, Höfle G (2000) Not all Myxobacterial Species are Equally Good Producers. In: Grabley S, Thiericke R (eds) Drug Discovery from Nature. Springer-Verlag, Berlin Heidelberg, p 173

25. Reichenbach H (2005) Genus I. Nannocystis Reichenbach 1970, 137AL. In: Brenner DJ, Krieg NR S, JT GG (eds) Bergey's Manual Of Systematic Bacteriology. Springer New York, pp 1137-1143

26. Reichenbach H, Dworkin M (1992) The Myxobacteria. In: The Prokaryotes. Springer, New York, pp 3416-3487 
27. Rolf Muller RG (2014) The Family Nannocystaceae. In: Rosenberg E, De Long EF, Loy S et al (eds) The Prokaryotes: Deltaproteobacteria and Epsilonproteobacteria, Fourth. Springer-Verlag, Berlin Heidelberg

28. Saadatpour F, Mohammadipanah F (2020) Bioprospecting of indigenous myxobacteria from Iran and potential of Cystobacter as a source of anti-MDR compounds. Folia Microbiol (Praha). https://doi.org/10.1007/s12223-019-00768-2

29. Shimkets LJ, Dworkin M, Reichenbach H (2006) The Myxobacteria. In: Dworkin M, Falkow S, Rosenberg E et al (eds) The Prokaryotes: Volume 7: Proteobacteria: Delta, Epsilon Subclass. Springer New York, New York, pp 31-115

30. von Jagow G, Ljungdahl PO, Graf P et al (1984) An inhibitor of mitochondrial respiration which binds to cytochrome $b$ and displaces quinone from the iron-sulfur protein of the cytochrome bc1 complex. J Biol Chem 259:6318-6326

31. Weissman KJ, Müller R (2010) Myxobacterial secondary metabolites: Bioactivities and modes-ofaction. Nat Prod Rep 27:1276-1295. https://doi.org/10.1039/c001260m

32. Yoon SH, Ha SM, Kwon S et al (2017) Introducing EzBioCloud: A taxonomically united database of 16S rRNA gene sequences and whole-genome assemblies. Int J Syst Evol Microbiol 67:1613-1617. https://doi.org/10.1099/ijsem.0.001755

33. Zhang T, Chen JH, Si JG et al (2018) Isolation, Structure Elucidation, and Absolute Configuration of Germacrane Isomers from Carpesium divaricatum. Sci Rep 8:12418. https://doi.org/10.1038/s41598-018-30782-2

34. Zhou XW, Li SG, Li W et al (2014) Myxobacterial community is a predominant and highly diverse bacterial group in soil niches. Environ Microbiol Rep 6:45-56. https://doi.org/10.1111/17582229.12107

\section{Figures}




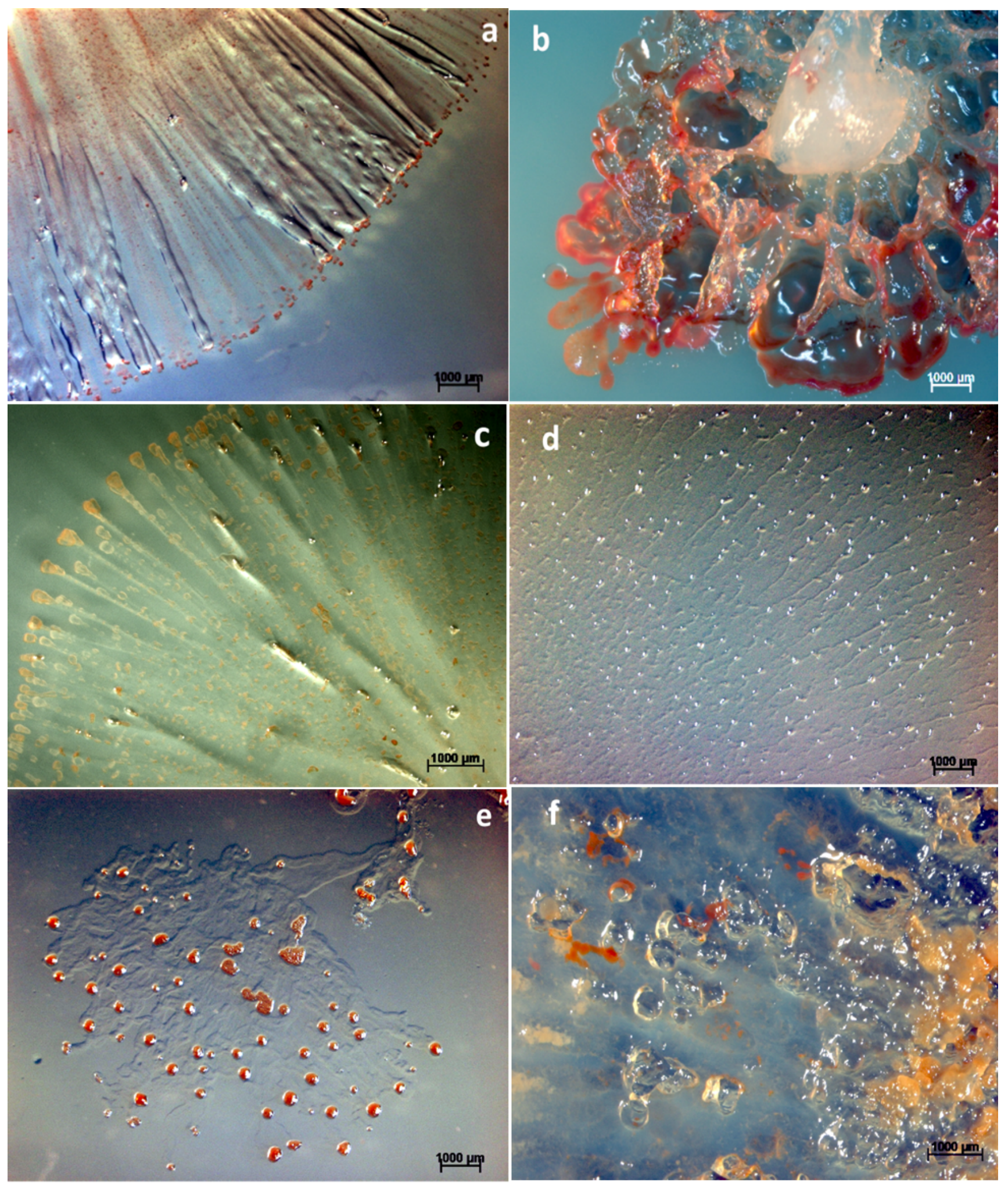

\section{Figure 1}

Morphology of Nannocystis strains on agar media. a) fan like swarm with the agar channeling of $\mathrm{N}$. pusilla 3 on the VY agar, the single sporangioles formed on the edge and trail of swarms; b) the extensive agar degradation by N. pusilla 25, the sporangioles grown onto the CY medium; c) swarm of N. pusilla 212 on $\mathrm{CY}$ agar resembled N. pusilla 3, note the less agar channeling; d) the tiny colorless sporangioles of $\mathrm{N}$. exedens 51 on VY agar, the agar degraded on the trail of swarming cells; e) the single and clustered 
sporangioles of $\mathrm{N}$. exedens 211 ditch $\mathrm{CY}$ agar but the sporangioles formed on the surface of solid media; f) $\mathrm{N}$. exedens 215 pits on the $\mathrm{CY}$ agar with clustered orange sporangioles.

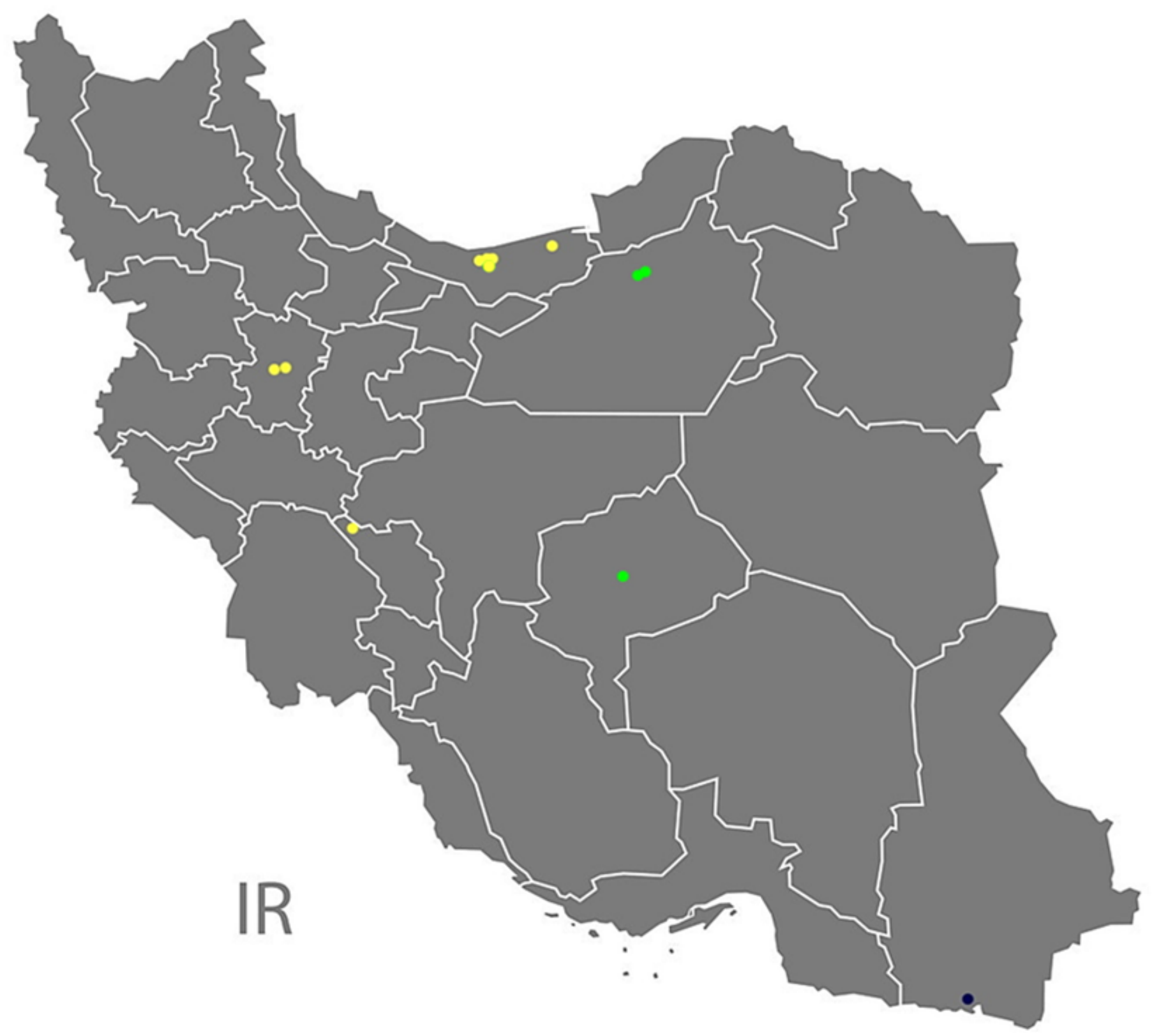

Figure 2

The approximate location of isolated strains in the Iran map. Yellow dots for N. pusilla, green dots for N. exedens, and navy blue for $\mathrm{N}$. konarekensis. 


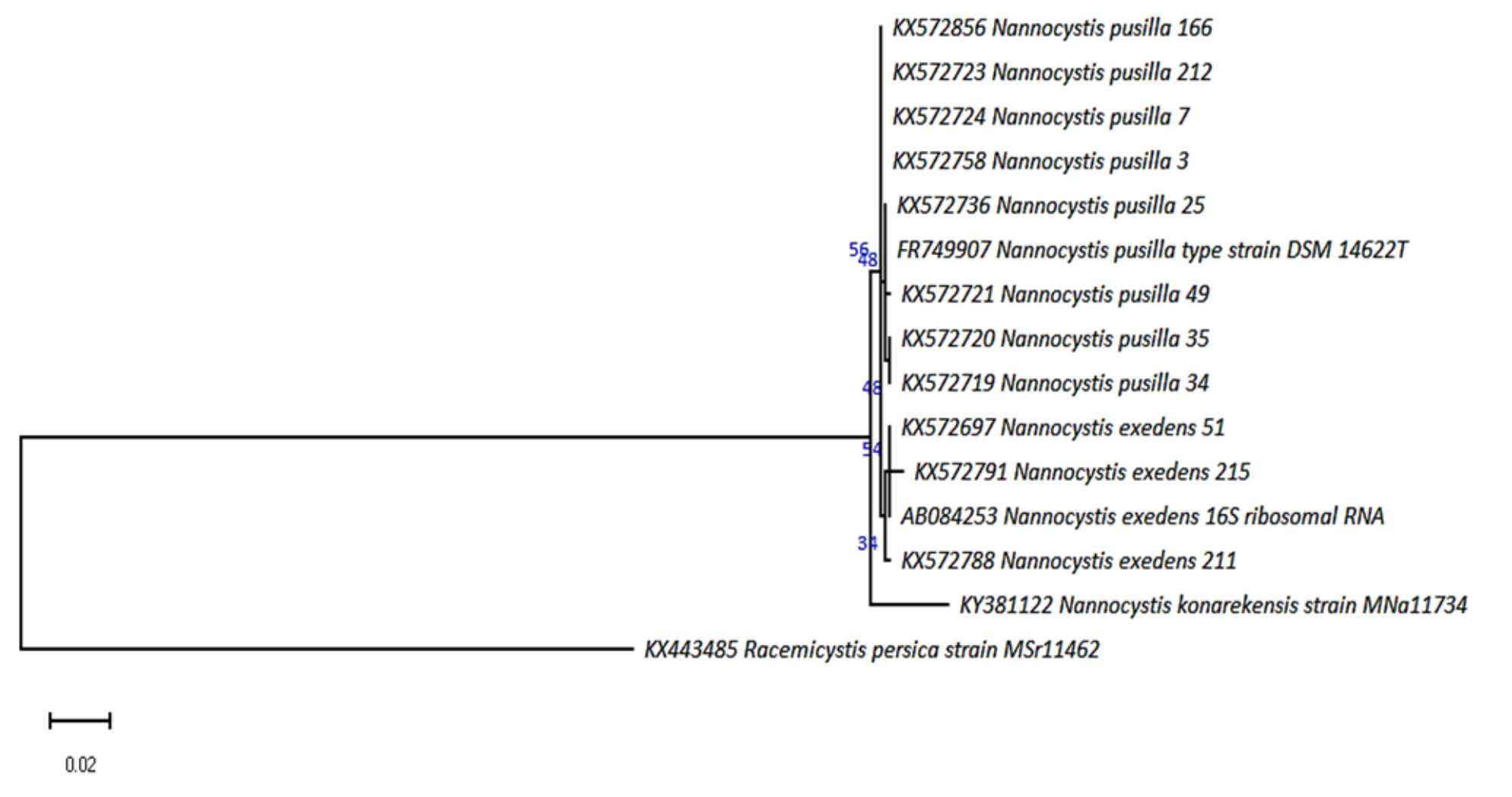

\section{Figure 3}

Phylogenetic relationship of strains resolved by the Maximum-Likelihood method and 100 resamplings. The accession number of isolates and bootstrap values are presented in the tree. Two type strains of $\mathrm{N}$. pusilla (FR749907) and N. exedens (AB084253) included; Racemicystis persica, a member of the Sorangiineae, was used as the outgroup to root the tree. 


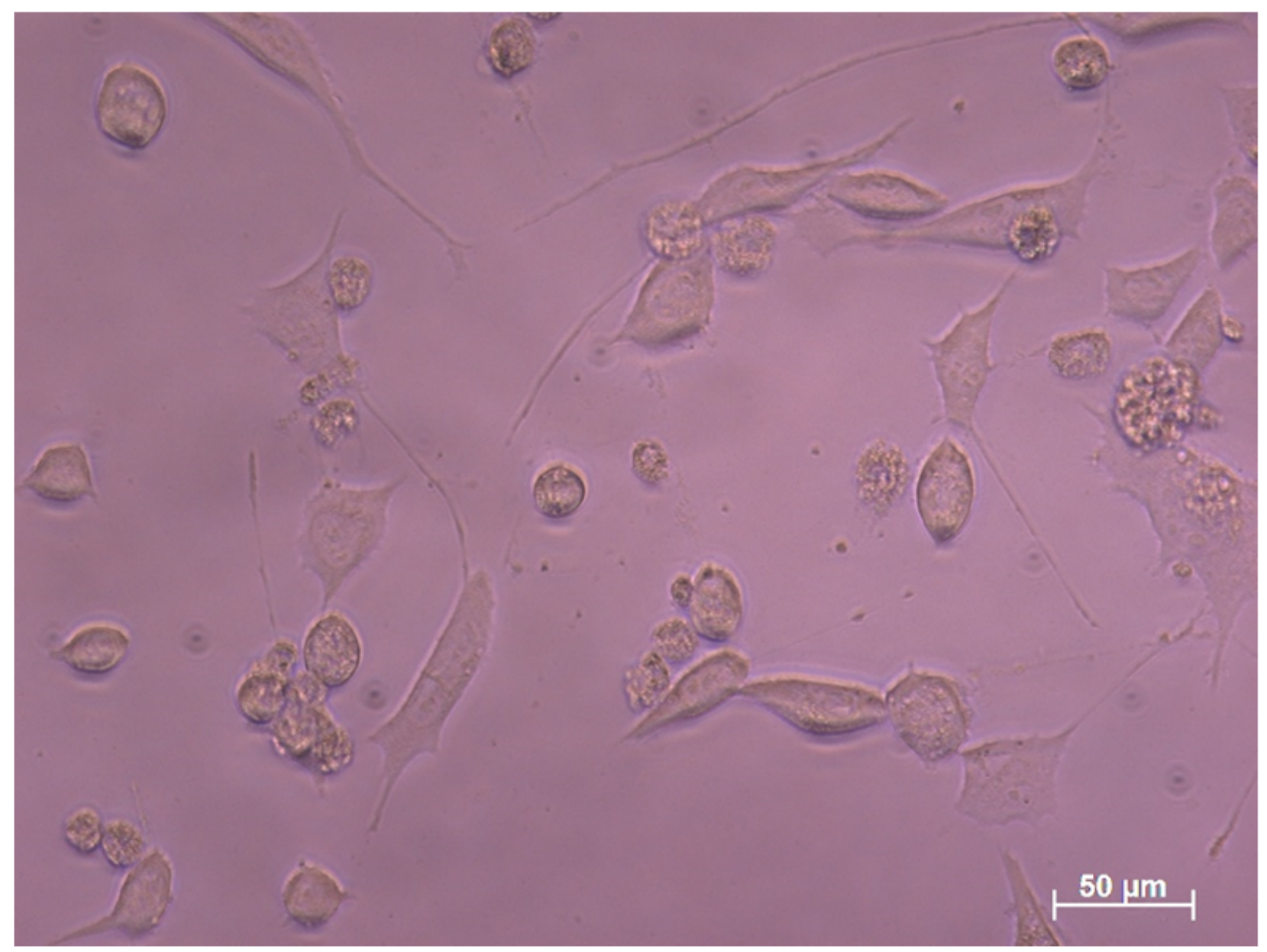

\section{Figure 4}

The cytotoxic effect on the L929 cell line was evident through vacuolation of cytoplasm only in the experiment by extract of strain 215 of $\mathrm{N}$. exedens. 


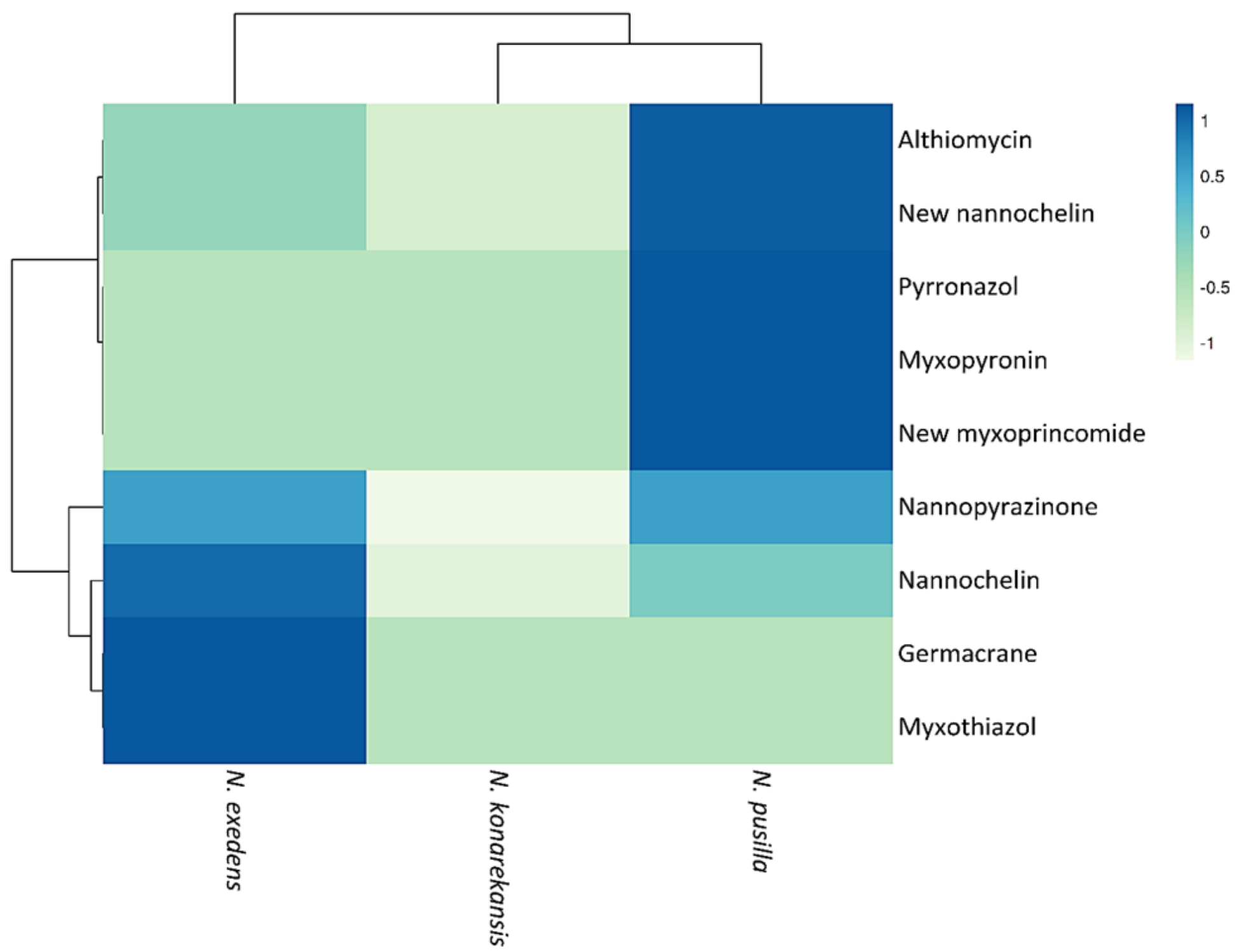

Figure 5

The heatmap revealed differently distributed natural products between Nannocystis species. Also, some secondary metabolites are strongly grouped in the graph. Nannopyarzinone and Nannochelins were produced evenly by both N. pusilla and N. exedens. 